\title{
Laryngeal mask airway without muscle relaxant in femoral head replacement in elderly patients
}

\author{
MING KONG* ${ }^{*}$, BEIPING LI* and YUNPING TIAN \\ Department of Anesthesiology, First People's Hospital of Xuzhou, Xuzhou, Jiangsu 221002, P.R. China
}

Received August 21, 2015; Accepted November 5, 2015

DOI: $10.3892 /$ etm.2015.2844

\begin{abstract}
The number of elderly patients undergoing femoral head replacement surgeries is on the increase. These patients often suffer from comorbidity such as cardiovascular and cerebrovascular complications, which limits the ability of medical teams to employ anesthesia. Thus, alternative methods are required. The aim of this study was to examine the advantage of laryngeal mask airway (LMA) in the absence of muscle relaxant in elderly patients undergoing femoral head replacement operations. Fifty patients (27 males and 23 females) undergoing femoral head replacements were selected for the study between March 2013 and May 2014. The mean value for the age in this group was $74.6 \pm 12.5$ years. The patients were randomly distributed into two groups of 25 . One group was designated as the treatment group and the second group as the control group. For the treatment group, LMA without muscle relaxant was used, and the control group received routine anesthesia. Variations in heart rate (HR), mean arterial pressure (MAP) and oxygen saturation $\left(\mathrm{SPO}_{2}\right)$ in the two groups were monitored at different times. Clinical efficacy and muscle relaxation effects were also analyzed. For the treatment group, the HR, MAP and $\mathrm{SPO}_{2}$ measurements did not reveal any significant variation while these values in the control group demonstrated important dissimilarities. Time to recovery, time to extubation and incidence of throat pain in the treatment group were all markedly decreased as compared to those in control group. The operation time in the treatment group was not significantly different to that of control group. The satisfaction of the muscle relaxation effect in the treatment group was significantly higher than that in the control group while the incidence of adverse reactions was not considerably different. In conclusion, the use of LMA without using muscle
\end{abstract}

Correspondence to: Yunping Tian, Department of Anesthesiology, First People's Hospital of Xuzhou, 19 Zhongshanbei Road, Xuzhou, Jiangsu 221002, P.R. China

E-mail: typing326@163.com

*Contributed equally

Key words: laryngeal mask airway, no-muscle-relaxant technology, femoral head replacement, elderly patients relaxant in femoral head replacement surgeries performed on elderly patients showed to be effective and safe.

\section{Introduction}

The number of elderly patients undergoing femoral head replacement surgeries is on the increase. These patients often suffer from comorbidity such as cardiovascular and cerebrovascular complications, which limits the ability of medical teams to utilize anesthesia (1). Inappropriate anesthesia is the main source of severe damage and comorbidity in $12.3 \%$ of cases undergoing femoral head replacement surgeries (2).

The introduction of laryngeal mask airway (LMA) by Brain (3) replaced the mask and endotracheal intubation and changed the traditional concept of airway management. At present, a 30-60\% laryngeal mask is applied in general anesthesia. However, the application rate at the Queen Elizabeth Hospital (Hongkong, China) was identified as $20 \%$ (4). LMA is considered convenient due to its easier airway maintenance, less gas leakage, and less pollution of the operating room. For patients undergoing a short-duration operation, LMA can replace the bag-mask device $(5,6)$. Clinical anesthesia induction is often performed under the premise of muscle relaxation, and muscle relaxation is primarily used to reduce the tracheal intubation response and muscle tension during general anesthesia, in order to provide suitable conditions for the operation. However, for patients with myasthenia gravis, obesity, sleep apnea syndrome and other complications, the use of a muscle relaxation agent is a debatable point $(7,8)$. At the same time, the use of muscle relaxation for minor surgery may affect the patient's recovery and delay the patient's respiratory recovery time (9). Laryngeal mask without muscle relaxant has been used in tumor removal, with a favourable outcome (10). In the present study, 50 cases of senile patients with femoral head replacement surgery were treated with LMA without muscle relaxant, resulting in a satisfactory effect outcome.

\section{Materials and methods}

General information. Fifty patients (27 males and 23 females) undergoing femoral head replacements were selected for the study between March 2013 and May 2014.

The patients were randomly distributed into two groups of 25 . One group was designated as the treatment 
group and the second group served as the control group. Fifteen male and 10 female patients with an age range of 60 - 89 years $(74.3 \pm 15.2$ years) were placed in the treatment group. The mean value for the weight in this group was $53.6 \pm 11.3 \mathrm{~kg}$. The control group comprised 12 males and 13 females with an age range of $61-88$ years $(75.4 \pm 12.6$ years). The mean value for the weight in this group was $52.8 \pm 10.7 \mathrm{~kg}$. Gender, age and weight of the patients did not significantly affected the results $(\mathrm{P}>0.05)$.

Inclusion criteria for the study required that each patient undergo examinations prior to surgery and had no anesthesia contraindication in the vertebral canal. Any patients with comorbidity received medical therapy to meet surgical requirements. Liver and renal functions as well as the coagulation function were measured after recovery.

Exclusion criteria for the current study were: i) Presence of any form of allergy to anesthetics; ii) existence of any type of endocrine disorders; iii) existence of any severe anemia prior to surgery including blood transfusion or blood loss of $>500 \mathrm{ml}$.

Thirty minutes prior to anesthesia, each patient received $1 \mathrm{mg}$ of penehyclidine hydrochloride intravenously. A hemodynamic monitor (Mindray, Shenzhen, China) was used to monitor the electrocardiogram, oxygen saturation $\left(\mathrm{SPO}_{2}\right)$ and mean arterial pressure (MAP). Sufentanil $(0.2 \mu \mathrm{g} / \mathrm{kg})$, propofol $(2 \mathrm{mg} / \mathrm{kg})$ and etomidate $(0.3 \mathrm{mg} / \mathrm{kg})$ were used for the treatment group. Opler no. 4 LMA (Vitaltec, Taichung, Taiwan) was inserted following completion of anesthesia. In those cases where the insertion failed twice, LMA was replaced with a tracheal catheter, and the patients were excluded from the treatment group. Criteria established for LMA positioning were: i) bilateral breath sound was required to be similar to that of prior to surgery with no succussion splash into the stomach; ii) peak end tidal $\mathrm{CO}_{2}$ level $\left(\mathrm{PETCO}_{2}\right)$ was required to be normal; iii) fiberoptic bronchoscopy test was performed.

For the control group, atracurium $(2 \mathrm{mg} / \mathrm{kg})$, sufentanil $(0.2 \mu \mathrm{g} / \mathrm{kg})$ and propofol $(0.6 \mathrm{mg} / \mathrm{kg})$ were prepared Subsequently, a tracheal catheter (diameter $7.0 \mathrm{~mm}$ ) was intubated and sufentanil $(0.1 \mu \mathrm{g} / \mathrm{kg} / \mathrm{h})$ and propofol $(4-8 \mathrm{mg} / \mathrm{kg} / \mathrm{h})$ were administered by continuous intravenous infusion, while atracurium was administered by intermittent intravenous infusion. Patients in the treatment and control groups were subjected to mechanical ventilation. Following completion of the surgeries the patients were subjected to a head lift of $>5 \mathrm{sec}$ and breathing for $5 \mathrm{~min}\left(\mathrm{SPO}_{2} \geq 95 \%\right)$ in order to regain consciousness. After extubation (withdrawal of LMA) or removal of the tracheal catheter, the patients were returned to the ward.

Monitoring measurements. Values for MAP, heart rate (HR) and $\mathrm{SPO}_{2}$ were recorded at different times: i) prior to anesthesia (T0), ii) immediately after intubation or indwelling of LMA (T1), iii) 10 min after intubation (T2), and iv) immediately after extubation or withdrawal of LMA (T3). Time to recovery, time to extubation, and frequency of postoperative throat pain were also recorded. Muscle relaxation was compared in patients in the two groups.

Statistical analysis. Statistical analysis was performed using SPSS 18.0 software. Categorical data were presented by numbers and percentages, and tested using the $\chi^{2}$ test. Quantitative data were presented by means \pm SD. Inter-group differences were analyzed using the t-test, and analysis of variance was performed between the groups. $\mathrm{P}<0.05$ indicated a statistically significant result.

\section{Results}

MAP, HR and $\mathrm{SPO}_{2}$ measurements at different times. The results of the monitoring of MAP, $\mathrm{HR}$ and $\mathrm{SPO}_{2}$ in the treatment and control groups prior to surgery did not demonstrate any significant difference $(\mathrm{P}>0.05)$. The results of monitoring MAP, HR and $\mathrm{SPO}_{2}$ indicated that routine anesthesia used for patients in the control group was potentially the source of the instability observed in MAP, HR and $\mathrm{SPO}_{2}$. MAP, HR and $\mathrm{SPO}_{2}$ values in the control group observed at different times were significantly different $(\mathrm{HR}, \mathrm{F}=2.301, \mathrm{P}=0.042$; MAP, $\left.\mathrm{F}=2.643, \mathrm{P}=0.036 ; \mathrm{SP}_{2}, \mathrm{~F}=1.955, \mathrm{P}=0.044\right)$. By contrast, the MAP, HR and $\mathrm{SPO}_{2}$ values for the patients in the treatment group were not significantly different $(\mathrm{P}>0.05)$. This result suggested that LMA without muscle relaxant in the treatment group resulted in a stable MAP, HR and $\mathrm{SPO}_{2}$ (Table I).

Clinical efficacy. Time to recovery, time to extubation and occurrence of throat pain in the treatment group were significantly less than those observed in the control group $(\mathrm{P}<0.05)$. The operation time for the treatment group was not significantly different compared to the control group $(\mathrm{P}>0.05)$ (Table II).

Muscle relaxation effect, adjuvant medications and incidence of adverse reaction. The muscle relaxation effect, adjuvant medications and incidence of adverse reaction for the treatment group were significantly higher than those observed in the control group $\left(\chi^{2}=3.231, \mathrm{P}=0.022\right)$. Three patients in the treatment group $(12.00 \%)$ received a combination of innovar and midazolam due to poor anesthesia, which was markedly lower than the number of patients in the control group that required the same intervention. In the control group, 11 patients $(44.00 \%)$ received a combination of innovar and midazolam, which was significantly higher than the values observed in the treatment group $\left(\chi^{2}=2.424, \mathrm{P}=0.035\right)$. No patient in either group suffered from severe comorbidity such as arrhythmia at the time of operation. While 3 patients in the treatment group (12.00\%) and 4 patients in the control group $(16.00 \%)$ suffered from nausea and vomiting, the incidence of adverse reactions between two groups was not statistically different $(\mathrm{P}>0.05)$ (Table III).

\section{Discussion}

Femoral neck fractures are common in the elderly. The majority of patients undergoing femoral head replacements are at risk for respiratory and circulatory comorbidity and massive hemorrhage (10). The elderly patients are often in the risk group for multi-system disorders and anesthesia complications due to age-associated reduced physiological functions (6). The surgical risk in these patients is also increased due to poor vascular compensation as well as qualitative and quantitative details of intraoperative 
Table I. MAP, HR and $\mathrm{SPO}_{2}$ at different times in the treatment and control groups.

\begin{tabular}{|c|c|c|c|c|c|c|}
\hline \multirow[b]{2}{*}{ Time } & \multicolumn{2}{|c|}{ HR (beat/min) } & \multicolumn{2}{|c|}{ MAP (mmHg) } & \multicolumn{2}{|c|}{$\mathrm{SPO}_{2}(\%)$} \\
\hline & Control & Treatment & Control & Treatment & Control & Treatment \\
\hline T0 & $81.48 \pm 10.95$ & $80.37 \pm 10.41$ & $79.81 \pm 9.87$ & $80.65 \pm 8.64$ & $98.67 \pm 1.69$ & $97.23 \pm 1.95$ \\
\hline $\mathrm{T} 1$ & $73.32 \pm 11.56$ & $74.58 \pm 13.61$ & $72.41 \pm 10.17$ & $73.37 \pm 12.89$ & $95.01 \pm 0.82$ & $98.00 \pm 0.94$ \\
\hline $\mathrm{T} 2$ & $72.71 \pm 10.46$ & $73.56 \pm 12.03$ & $70.56 \pm 10.29$ & $73.41 \pm 10.41$ & $94.01 \pm 0.76$ & $97.00 \pm 0.55$ \\
\hline $\mathrm{T} 3$ & $70.08 \pm 12.18$ & $73.48 \pm 13.52$ & $68.55 \pm 11.97$ & $72.52 \pm 14.02$ & $94.19 \pm 1.26$ & $96.52 \pm 1.73$ \\
\hline
\end{tabular}

$\mathrm{HR}$, heart rate; MAP, mean arterial pressure; $\mathrm{SPO}_{2}$, oxygen saturation.

Table II. Clinical efficacy in the treatment vs. control group.

\begin{tabular}{lccccc}
\hline Group & No. & Time to recovery (min) & Time to extubation (min) & Operation time (min) & Throat pain [number $(\%)]$ \\
\hline Treatment & 25 & $35.67 \pm 16.44$ & $7.38 \pm 2.17$ & $123.45 \pm 46.67$ & $2(8.00)$ \\
Control & 25 & $45.87 \pm 20.31$ & $11.53 \pm 3.74$ & $119.72 \pm 36.69$ & $9(36.00)$ \\
T $\left(\chi^{2}\right)$ & & 2.854 & 3.014 & 0.947 & 3.947 \\
P-value & & 0.031 & 0.026 & 0.686 & $<0.001$ \\
\hline
\end{tabular}

Table III. Muscle relaxation effect and adjuvant medications in the treatment and control groups.

\begin{tabular}{|c|c|c|c|c|c|c|}
\hline \multirow[b]{2}{*}{ Group } & \multirow[b]{2}{*}{ Number } & \multicolumn{3}{|c|}{ Muscle relaxation effect } & \multicolumn{2}{|c|}{ Adjuvant medications } \\
\hline & & Satisfactory (n/\%) & Good & Poor & Innovar & Midazolam \\
\hline Treatment & 25 & $21(84.00)$ & $3(12.00)$ & $1(4.00)$ & 2 & 1 \\
\hline Control & 25 & $14(56.00)$ & $8(32.00)$ & $3(12.00)$ & 5 & 6 \\
\hline
\end{tabular}

medications (5). Consequently, methods of anesthesia should be selected diligently for these patients. The use of LMA without muscle relaxant can be considered as an ideal method of anesthesia in femoral head replacement surgeries for elderly patients. This method offers a good balance between the efficiency and the safety. In addition, use of this method can reduce the intraoperative instability of blood pressure and HR (6-8). SLIPA LMA is an advanced supraglottic ventilation device similar to human pharyngeal anatomical structure. The absence of air charge cell in SLIPA LMA can prevent recurrent laryngeal nerve injuries caused by the dilatation of the upper esophagus $(2,11)$. This anesthetic procedure is convenient in clinic and has a relatively high success rate. Intubation of trachea cannula is often complicated and the indwelling of laryngoscope may irritate the glottis and trachea, and can result in hemodynamic changes $(6,12)$. In this study, all the patients successfully completed the indwelling and we demonstrated that stable HR, MAP and $\mathrm{SPO}_{2}$ can be obtained using LMA without muscle relaxant.

No significant differences were identified in the HR, MAP and $\mathrm{SPO}_{2}$ values at different times in patients in the treatment group. This finding was associated with the fact that laryngoscope was not directly indwelled in LMA. Thus, the vocal cord and tracheal mucosa were not affected, and the sympathetic nerve was not excessively stimulated $(13,14)$. Furthermore, compared with the results of earlier studies, the time to recovery and time to extubation were decreased for the patients in the treatment group compared to those in the control group (15). The incidences of throat pain for patients in the treatment group were inferior to those of the control group, which was consistent with previously reported studies (16). These results may be attributed to the fact that indwelling of SLIPA LMA requires no air inflation and may not produce overcompression to the throat cavity wall $(4,17)$. Although SLIPA LMA required no air inflation, it contained a 50-ml cavity for secretion in order to prevent error aspiration $(18,19)$. Of note, the use of SLIPA LMA in patients with full or residual stomach contents should be considered prudently (20).

In conclusion, the method of using the SLIPA LMA without muscle relaxant in femoral head replacement surgeries is a superior method that offers stable hemodynamics, postoperative consciousness, early extubation and less throat pain in elderly patients. 


\section{References}

1. Fleisher LA: Geriatric anesthesia: can we achieve the goal of returning our elderly to the baseline or improved function? Anesthesiol Clin 33: xiii-xiv, 2015.

2. Oda Y, Tanaka K, Matsuura T, Hase I, Nishikawa K and Asada A: Nitrous oxide induces paradoxical electroencephalographic changes after tracheal intubation during isoflurane and sevoflurane anesthesia. Anesth Analg 102: 1094-1102, 2006.

3. Brain AI: Three cases of difficult intubation to overcome by the laryngeal mask airway. Anesthesia 40: 353-355, 1985.

4. El-Dawlatly AA: Anesthesia for thoracoscopic thymectomy: Modified non-muscle relaxant technique-case reports. Middle East J Anaesthesiol 19: 219-224, 2007.

5. Bagshaw O: A combination of total intravenous anesthesia and thoracic epidural for thymectomy in juvenile myasthenia gravis Paediatr Anaesth 17: 370-374, 2007.

6. Al-Mazrou KA, Abdullah KM, ElGammal MS, Ansari RA, Turkistani A and Abdelmeguid ME: Laryngeal mask airway vs. uncuffed endotracheal tube for nasal and paranasal sinus surgery: Paediatric airway protection. Eur J Anaesthesiol 27: 16-19, 2010.

7. Miller DM: A proposed classification and scoring system for supraglottic sealing airways: A brief review. Anesth Analg 99: 1553-1559, 2004

8. Miller DM and Camporota L: Advantages of ProSeal and SLIPA airways over tracheal tubes for gynecological laparoscopies. Can J Anaesth 53: 188-193, 2006.

9. Ledowski T: Muscle relaxation in laparoscopic surgery: what is the evidence for improved operating conditions and patient outcome? A brief review of the literature. Surg Laparosc Endosc Percutan Tech 25: 281-285, 2015.

10. Kim YH, Kim JS, Park JW and Joo JH: Total hip replacement with a short metaphyseal-fitting anatomical cementless femoral component in patients aged 70 years or older. J Bone Joint Surg Br 93: 587-592, 2011.
11. Hooshangi H and Wong DT: Brief review: the Cobra Perilaryngeal Airway (CobraPLA and the Streamlined Liner of Pharyngeal Airway (SLIPA) supraglottic airways. Can J Anaesth 55: 177-185, 2008.

12. Pokee $\mathrm{N}$ and Wiwanitkit V: Thiopentone sodium and propofol for facilitation of laryngeal mask airway insertion. Ann Afr Med 14: 160-161, 2015.

13. Gopinath MV, Ravishankar M, Nag K, Kumar VH, Velraj J and Parthasarathy S: Estimation of effect-site concentration of propofol for laryngeal mask airway insertion using fentanyl or morphine as adjuvant. Indian J Anaesth 59: 295-299, 2015.

14. Nisi F, Galzerano A, Cicchitto G, Puma F and Peduto VA: Improving patient safety after rigid bronchoscopy in adults: Laryngeal mask airway versus face mask - a pilot study. Med Devices (Auckl) 8: 201-206, 2015.

15. Cook TM and Kelly FE: Time to abandon the 'vintage' laryngeal mask airway and adopt second-generation supraglottic airway devices as first choice. Br J Anaesth 14: 136-137, 2015.

16. Tanoubi I, Sun JN, Drolet P, Fortier LP and Donati F: Replacing a double-lumen tube with a single-lumen tube or a laryngeal mask airway device to reduce coughing at emergence after thoracic surgery: A randomized controlled single-blind trial. Can J Anaesth 62: 988-995, 2015.

17. Baftiu N, Hadri B, Morina M and Mustafa A: Anesthesia for trans-sternal thymectomy: Modified non-muscle relaxant technique. Med Arh 65: 317-318, 2011.

18. Tortosa JA and Hérnández-Palazón J: Anaesthesia for laparoscopic cholecystectomy in myasthenia gravis: A non-muscle relaxant technique. Anaesthesia 52: 807-808, 1997.

19. Chan MT, Ng SK and Low JM: A non-muscle-relaxant technique for video-assisted thoracoscopic thymectomy in myasthenia gravis. Anaesth Intensive Care 23: 256-257, 1995.

20. el-Dawlatly AA and Ashour MH: Anaesthesia for thymectomy in myasthenia gravis: A non-muscle-relaxant technique. Anaesth Intensive Care 22: 458-460, 1994. 